\title{
Treatment patterns and survival among older adults in the United States with advanced soft-tissue sarcomas
}

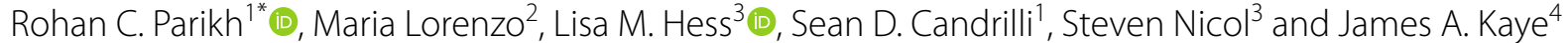

\begin{abstract}
Background: To describe patient and tumor characteristics, treatments, and survival among older adults in the United States with advanced soft-tissue sarcoma (STS), across and by categories of specifically defined histologic subtypes.
\end{abstract}

Methods: We conducted a retrospective cohort analysis using the SEER. The study population comprised patients $\geq 65$ years old with advanced STS (excluding osteosarcoma, Kaposi sarcoma, and gastrointestinal stromal tumors) diagnosed from January 1, 2001 to December 31, 2011.

Results: Of 4274 study patients, 2103 (49.2\%) were male. Mean age was 77.8 years, and 1539 (36.0\%) had distant disease at initial diagnosis. The most common histologic categories were leiomyosarcoma (922[21.6\%]), undifferentiated pleomorphic sarcoma (652[15.3\%]), and liposarcoma (554[13.0\%]). Overall, 1227 (28.7\%) patients received first-line systemic therapy. Among these patients, 325 (26.5\%) received docetaxel plus gemcitabine and 231 (18.8\%) received doxorubicin alone. Only 476 patients received second-line therapy (11.1\%), most commonly doxorubicin alone $(n=101)$. Median overall survival $(95 \%$ confidence interval) from advanced STS diagnosis was $8.9(8.3,9.7)$ months.

Conclusions: Although previous studies of younger populations reported anthracycline-based therapy predominated in first line, our study of older advanced STS patients found that docetaxel plus gemcitabine was most commonly used. Despite variation by histologic category, prognosis remains poor for older adult patients with advanced STS.

Keywords: Soft-tissue sarcoma, Chemotherapy, Observational study

\section{Background}

Soft-tissue sarcoma (STS) refers to a rare and heterogeneous group of malignant tumors comprising more than 50 histologic subtypes derived from connective tissues and other cells of mesenchymal origin. Soft-tissue sarcoma accounts for approximately $1 \%$ of all incident malignancies [1] and an estimated 13,040 new cases will be diagnosed in the United States (US) in 2018, with 7370 dying from the disease [2]. In 2014, the age-adjusted incidence rate, for STS for patients 65 years of age and older

\footnotetext{
*Correspondence: rparikh@rti.org

${ }^{1}$ RTI Health Solutions, 200 Park Offices Drive, Research Triangle Park, NC 27560, USA

Full list of author information is available at the end of the article
}

was 11.3 per 100,000 , compared to 2.3 per 100,000 for patients younger than 65 years of age [3].

Among all patients diagnosed with STS, the 5-year overall survival is approximately 50\% [4]. Tumor histology, stage, and primary site are prognostic factors $[4$, 5]; 5-year overall survival is $83 \%$ in patients with localized disease and $16 \%$ in patients with distant metastases at initial diagnosis [6]. Eventually, either at initial diagnosis or after recurrence from a more limited extent of disease, $40-50 \%$ of patients with STS will have metastatic or unresectable locally-advanced disease (collectively referred to as "advanced STS") [7].

Treatment options for patients with advanced STS have historically been limited; cytotoxic chemotherapy has been the mainstay of therapy for decades. Active drugs 
include doxorubicin, ifosfamide, gemcitabine, taxanes, and several others; these may be administered either as single agents or in combination regimens $[4,8]$. The intent of these treatments is palliative for the majority of patients $[4,8,9]$. Until recently, clinical trials-including those demonstrating superiority of combination chemotherapy over monotherapy and those leading to the regulatory approval of newer agents such as olaratumab, trabectedin, and pazopanib-have found improvements in response rates and progression-free survival $[4,10-$ 14]. However, olaratumab is the only newer agent to date that has also demonstrated a statistically significant improvement in overall survival [11].

Few studies have examined utilization of systemic treatments for STS in the general population of the US, especially in older patients with advanced disease. Furthermore, there is little published information on variation in outcomes according to tumor histology, especially among older adults. Thus, the objectives of this study were to describe real-world, population-based treatment patterns and survival among older adult patients with advanced STS, overall and by groupings of specific histologic subtypes (hereafter "histologic categories").

\section{Methods}

\section{Data source}

The Surveillance, Epidemiology, and End Results (SEER), which contains administrative claims data for Medicare enrollees, was used for the study. The SEER cancer registry comprises nine state population-based and seven metropolitan or regional population-based registries that routinely collect information on $98 \%$ of newly diagnosed (incident) cancer cases, in persons residing in SEER areas [15]. SEER areas have been shown to be nationally representative [16] and capture approximately one-quarter of the total US population [15].

Along with detailed information on incident cancer, the database provides comprehensive longitudinal health care utilization data from Medicare. The Medicare claims database provides information on all services covered under Medicare Part A benefits, including inpatient, skilled nursing facility, home health care, and hospice care. In addition, the database provides information on approximately $95 \%$ of services covered under Medicare Part B, including physician visits, outpatient care, durable medical equipment, and home health care. This study was deemed exempt from Institutional Review Board review in accordance with the US Code of Federal Regulations [45CFR46.101(b)] as these data do not contain any variables that could identify an individual subject either directly or indirectly.

\section{Study population}

Patients with a new diagnosis of STS between January 1, 2001 and December 31, 2011 were eligible for this study. Medicare claims data were available through 2013. Patients with STS (except osteosarcoma, Kaposi sarcoma, and gastrointestinal stromal tumors) were identified in the SEER database using International Classification of Diseases for Oncology, 3rd Edition (ICD-O-3), morphology codes as listed in Appendix 1: Table 6 [17]. In order to reduce the number of strata analyzed specific histologic subtypes (i.e., individual ICD-O-3 codes) were grouped into broader categories for analysis based on the 2013 World Health Organization's (WHO) Classification of Tumours of Soft Tissue and Bone [18]: (1) leiomyosarcoma (smooth muscle tumors), (2) undifferentiated pleomorphic sarcoma (UPS; previously known as malignant fibrous histiocytoma), (3) liposarcoma (adipocytic tumors), (4) vascular sarcomas, (5) fibroblastic/ myofibroblastic sarcoma, (6) nerve sheath sarcoma, (7) rhabdomyosarcoma (skeletal muscle tumors), (8) synovial sarcoma, and (9) others or not otherwise specified (NOS). The term "histologic category" was used in this study to distinguish these categories from the individual "histologic subtypes" they contain.

Advanced disease was defined as metastatic disease or as the presence of nodal metastases and no surgery (assuming patients who did not receive surgery were not suitable for surgical resection). Metastatic disease and nodal metastases were identified using the American Joint Commission on Cancer's Cancer Staging Manual [19] or the National Cancer Institute's (NCI's) SEER Summary Staging Manual [20]. Patients were also considered to have advanced STS if they had an initial diagnosis of localized disease with later progression to advanced STS as identified by either a medical claim with an International Classification of Diseases, 9th Revision, Clinical Modification (ICD-9-CM) diagnosis code for a secondary neoplasm (ICD-9-CM 196.0-198.89) or initiation of systemic therapy more than 6 months after surgery. The 6-month lag period was chosen to avoid interpreting adjuvant therapy as treatment for advanced disease.

Additionally, eligible patients were 65 years or older at the time of advanced STS diagnosis and were enrolled in both Medicare parts A and B without any health maintenance organization (HMO) enrollment from 6 months before initial STS diagnosis to death or end of study. Patients with HMO coverage (provided outside of the Medicare system) were excluded because claims data for these patients would not be complete, as the linked data for this study were limited to Medicare. Of the patients initially diagnosed with localized or regional disease according to SEER data, only those with evidence of 
advanced STS in Medicare claims that occurred at a date later than the initial STS diagnosis were included in the study (i.e., patients were excluded if there were contradictory initial diagnosis codes [i.e., localized or regional STS diagnosis and secondary neoplasm claims] on the same date, or if patients had no surgery after initial STS diagnosis and no secondary neoplasm claim). Study index date for each patient (start of follow-up) was defined as the date of the first observed evidence of advanced STS.

\section{Demographic and clinical characteristics}

Demographic characteristics including age, sex, race, SEER registry location, and urban or rural residency were tabulated. Clinical characteristics that were assessed at initial STS diagnosis included cancer stage, tumor location, and histologic subtype (with subsequent categorization described previously). We also computed a modified Charlson Comorbidity Index (CCI) score to obtain a measure of each patient's overall comorbidity burden at the time of the index diagnosis [21-23]. CCI scores were calculated for each patient based on evidence of the relevant diagnoses from 6-months prior to advanced STS diagnosis to advanced STS diagnosis (i.e., during 6-month pre-index date period). ICD-9-CM diagnosis codes for cancer were excluded from the CCI calculation for this study so as to not overestimate the baseline comorbidity burden, as all patients in this study had cancer.

\section{Treatment patterns}

Treatments were identified using evidence of relevant Healthcare Common Procedure Coding System (HCPCS) codes, ICD-9-CM procedure codes, and certain ICD-9-CM diagnostic codes and administrative revenue codes. In addition to HCPCS and ICD-9-CM codes, Medicare Part D prescription data were used to identify chemotherapy use for a subset of the cohort with this data (2007-2012). Among patients who received systemic treatment, up to five lines of treatment were identified. Specific therapies were examined based upon options included in the National Comprehensive Cancer Network (NCCN) Guidelines [24]. First-line treatment was examined among all patients, with at least one claim for an HCPCS-identifiable chemotherapeutic, biologic, or targeted therapy agent after their index date. The first observed date of treatment after the index date signaled the start of first-line treatment. First-line treatment was defined as the combination of all agents observed within 21 days after (and inclusive of) treatment initiation. After the end of this 21-day period, the use of any new agent signaled the start of the next line of treatment. Discontinuation of one or more of the agents without the addition of another agent was not considered a new line of treatment. In addition, patients with at least 6 months between apparent cessation of their previous line of treatment and reuptake of an identical regimen were defined as having initiated a next line of treatment. End of a line of treatment was defined as: (1) a 6-month gap in treatment regimen, (2) interruption by next line of treatment, or (3) treatment continuation until the end of study or death. Cancer-directed therapy was defined as receipt of any of broad treatment categories of surgery, radiation, chemotherapy, biologic therapy, or targeted therapy, while supportive care was defined as no receipt of treatment from any of the broad cancer-directed therapies.

\section{Statistical analyses}

Descriptive statistics [i.e., means, medians, ranges, and standard deviations (SDs) of continuous variables and frequency counts and percentages for categorical variables] were computed. Overall survival from advanced STS diagnosis was measured using the death information available from SEER and Medicare data, and survival time end points were analyzed using the Kaplan-Meier estimates with median survival time and 95\% confidence intervals (CIs) reported in months. Patients alive at the end of study period were censored for this analysis. Treatment patterns and survival were assessed in the overall advanced STS population and by histologic category. Additionally, survival was estimated separately for patients who received cancer-directed treatment and those who received supportive care only. All analyses were conducted using SAS Version 9.4 (Cary, NC: SAS Institute, Inc.; 2011). The SEER-Medicare data use agreement required that no cell sizes less than 11 be reported for any demographic or other characteristic, or combination of characteristics; thus, if sufficient sample size was not available, data were not reported and indicated with “-".

\section{Results}

A total of 4274 patients with advanced STS met the inclusion criteria for this study (Table 1). Patients were on average 77.8 years of age (SD, 7.3; range 65-104 years) at the time of advanced STS diagnosis and $49.2 \%$ were male (Table 2). The mean (SD) CCI score was 2.8 (2.33), and $69.2,18.3$, and $6.5 \%$ of patients had a history of hypertension, congestive heart failure, and myocardial infarction, respectively.

At initial diagnosis, $36.0 \%$ of patients had metastatic (distant) disease; the remaining majority (64.0\%) were diagnosed at earlier stages of disease and had claims based indicators of progression to advanced STS (Table 2) with a mean (SD) interval of 16.6 (23.0) months from initial diagnosis. Nodal disease (without any distant metastases) was observed only among $1.6 \%$ of patients at 
Table 1 Study population selection process

\begin{tabular}{|c|c|}
\hline & $\begin{array}{l}\text { Number } \\
\text { of patients }\end{array}$ \\
\hline Initial sample included in the SEER database & 142,689 \\
\hline Initial diagnosis date on or after January 1, 2001 & 135,608 \\
\hline Patients whose first diagnosis recorded in the SEER database was STS & 21,167 \\
\hline Patients with evidence (i.e., claim in Medicare data or diagnosis in SEER database) of metastatic disease & 8537 \\
\hline Initially diagnosed at metastatic stage ${ }^{a}$ & 3391 \\
\hline Initially diagnosed at non-metastatic stage ${ }^{a}$ & 5146 \\
\hline Patients 65 years or older at time of metastatic STS diagnosis & 6712 \\
\hline Patients who were alive at initial diagnosis of STS (i.e., reporting source other than autopsy or death certificate) & 6705 \\
\hline Patients who were not enrolled in an HMO for at least 6 months prior to initial diagnosis of STS to end of follow-up period & 5166 \\
\hline $\begin{array}{l}\text { Patients who have continuous enrollment in Medicare Part A and B (non-HMO) for at least } 6 \text { months prior to initial diagnosis of STS until } \\
\text { end of follow-up period }\end{array}$ & 4353 \\
\hline Patients who are not lost to follow-up prior to the assigned advanced STS diagnosis date ${ }^{b}$ & 4324 \\
\hline $\begin{array}{l}\text { Patients with a date of advanced STS diagnosis different than initial STS diagnosis (patients excluded if no surgery after initial STS diagno- } \\
\text { sis and no secondary neoplasm claim) }\end{array}$ & 4298 \\
\hline $\begin{array}{l}\text { Patients with a date of advanced STS diagnosis different than initial STS diagnosis (patients excluded if initial STS diagnosis and secondary } \\
\text { neoplasm claim on the same date) }\end{array}$ & 4274 \\
\hline Final study population & 4274 \\
\hline
\end{tabular}

HMO health maintenance organization, SEER Survey, Epidemiology, and End Results, STS soft-tissue sarcoma

a Only for descriptive purposes and no exclusion was made based on this criterion

b Day of diagnosis, which is reported as month and years, was assigned as 15 th of each month and hence some patients who either die or are lost to follow-up before the 15 th of the month have a negative length of follow-up

initial diagnosis. The most common histologic category was leiomyosarcoma $(n=922 ; 21.6 \%)$, followed by UPS $(\mathrm{n}=652 ; 15.3 \%)$, liposarcoma $(\mathrm{n}=554 ; 13.0 \%)$, vascular sarcoma $(n=357 ; 8.4 \%)$, fibroblastic/myofibroblastic sarcoma $(n=227 ; 5.3 \%)$, nerve sheath sarcoma $(n=106$; $2.5 \%)$, rhabdomyosarcoma $(\mathrm{n}=98 ; 2.3 \%)$, and synovial sarcoma $(n=49 ; 1.1 \%)$; the remaining $30.6 \%(n=1309)$ had other or NOS histologic categories. A few variations in patient and tumor characteristics by tumor histology were evident: $66.7 \%$ of patients with leiomyosarcoma were female; patients with synovial sarcoma had a mean age of 74.1 years, and $54.1,40.8,48.7 \%$ of patients with rhabdomyosarcoma, synovial sarcoma, and other/NOS histology, respectively, had distant stage of disease at initial STS diagnosis (Table 2). Overall, the most common specified anatomic tumor site was lower limb (21.9\%) (Appendix 2: Table 7), and the most common known tumor grade was undifferentiated (30.7\%) (Table 2). The average observed follow-up time from advanced STS diagnosis was 1.7 years (SD, 2.36) (Table 2).

Cancer-directed treatment was received by $62.1 \%$ of patients. Radiation was received by $40.0 \%$ of patients and surgery was received by $10.3 \%$ of patients. The mean (SD) age of patients who received cancer-directed treatment was 76.5 (6.9) years and the mean (SD) CCI score was 2.5 (2.1), with hypertension, diabetes (without complications), chronic pulmonary disease, peripheral vascular disease, and congestive heart failure observed among $68.9,28.4,24.4,18.1$, and $14.6 \%$ of patients, respectively (Additional file 1: Table S1). Chemotherapy, biologic therapy, and targeted therapy were received by $27.5,1.9$, and $1.3 \%$ of patients, respectively. Among the $28.7 \%$ of all patients with advanced STS who received chemotherapy, biologic therapy, or targeted therapy $(n=1227)$, the mean duration of first-line therapy was 4.1 months (SD, 4.1) (Table 3). Second-line therapy was received by $11.1 \%$ $(\mathrm{n}=476)$ of all patients; the mean duration of secondline treatment was 4.6 months (SD, 5.3). Among the 4.4\% of all patients with advanced STS who received at least third-line therapy $(n=189)$, the mean duration of thirdline therapy was 4 months (SD, 3.4). The proportion of patients receiving up to three lines of treatment and duration of each line of treatment by histologic category is shown in Table 3. First-line chemotherapy was most commonly received by patients with synovial sarcoma (42.9\%), leiomyosarcoma (37.0\%), and vascular sarcoma (36.4\%).

Overall, the most common regimen during first-line therapy was docetaxel plus gemcitabine $(26.5 \%)$, followed by doxorubicin monotherapy (18.8\%), gemcitabine monotherapy (9.1\%), paclitaxel monotherapy (5.5\%), and bevacizumab monotherapy (3.3\%). Docetaxel plus gemcitabine was the most common first-line therapy for patients with all histologic categories except liposarcoma 


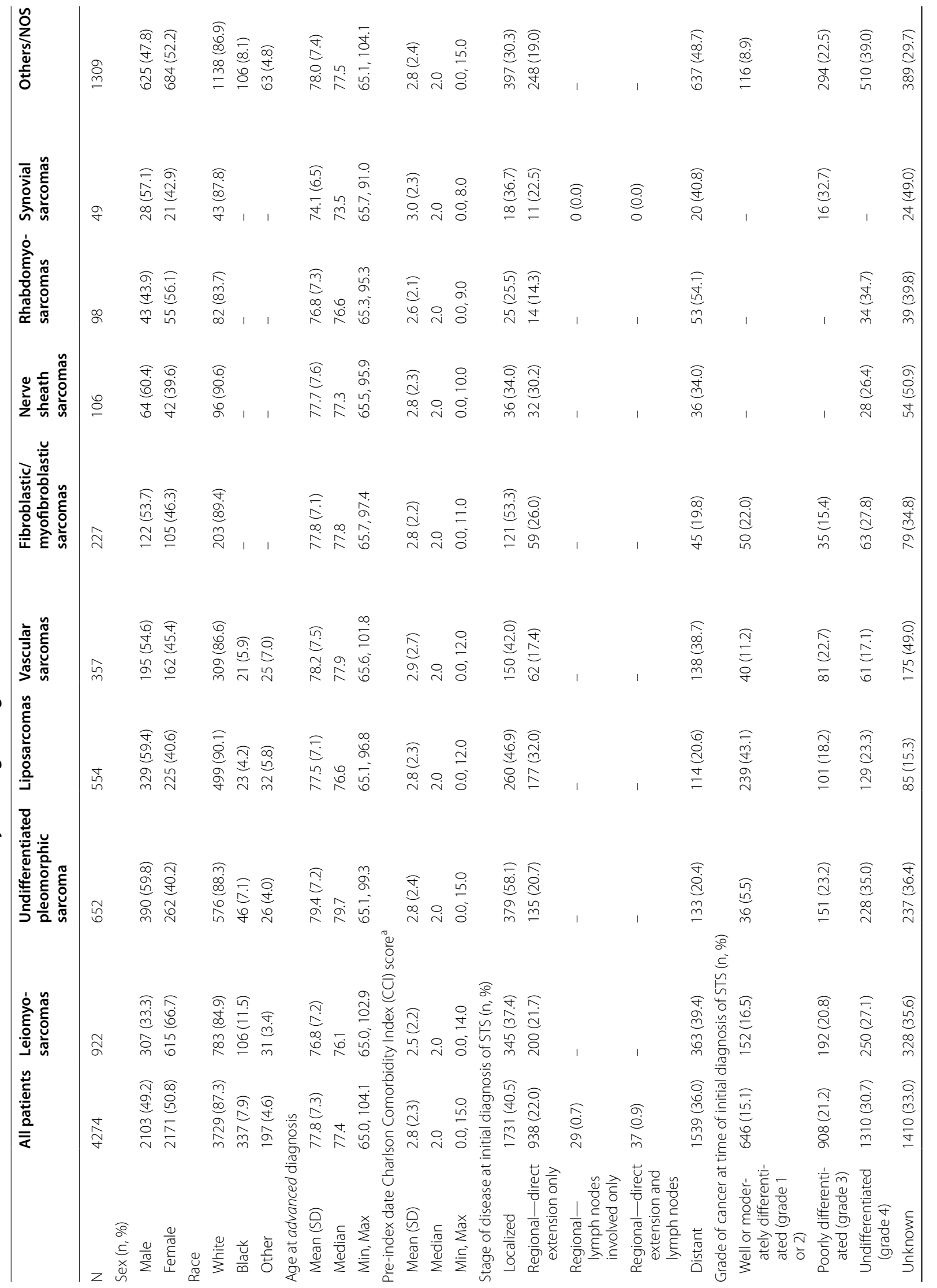




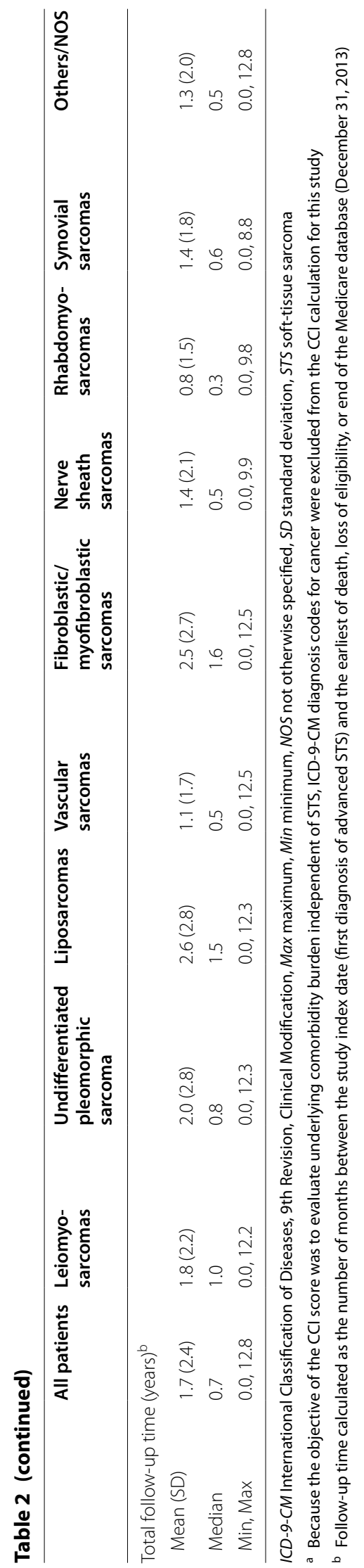




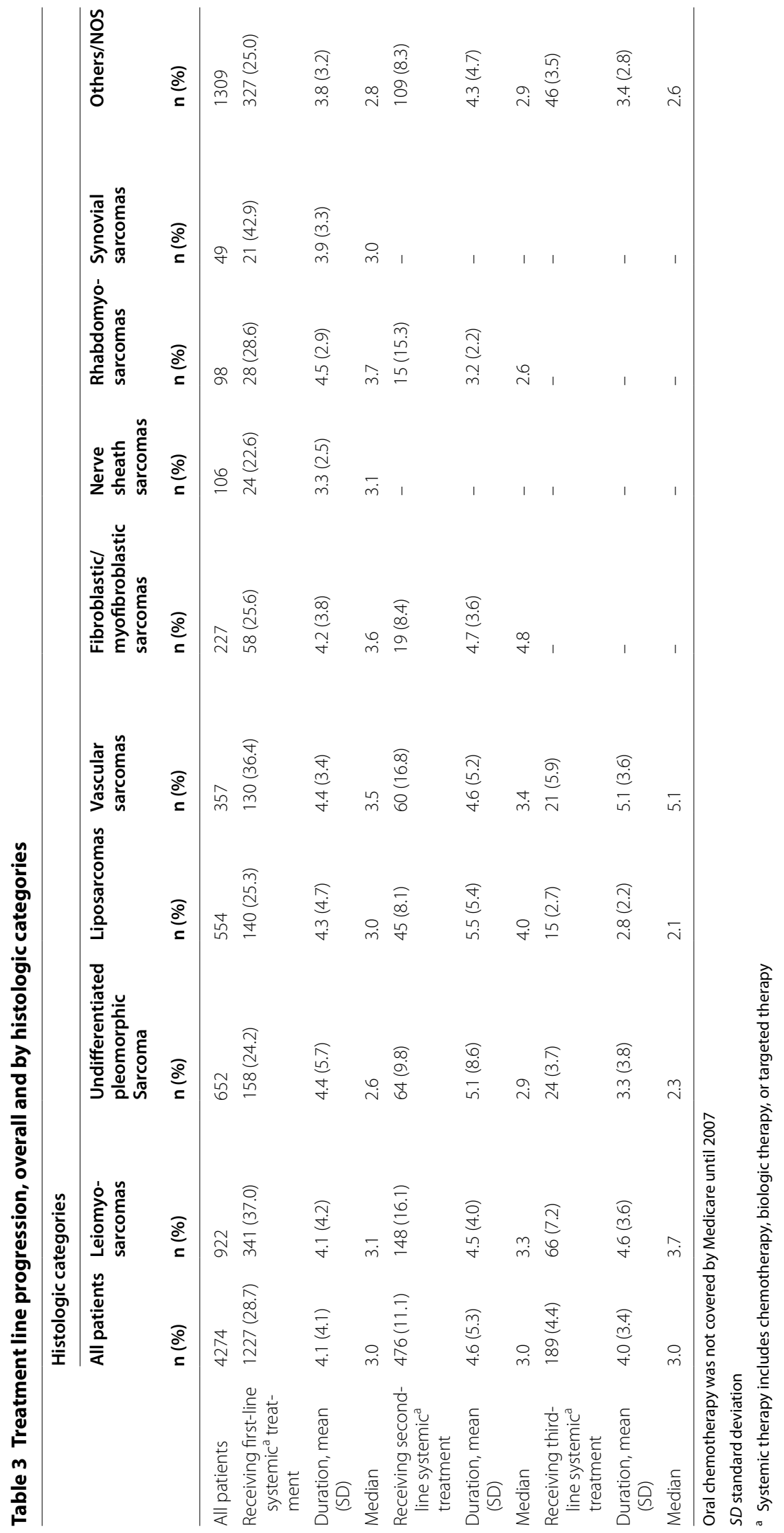


(for whom it was doxorubicin monotherapy [24.3\%]) and vascular sarcoma (for whom it was paclitaxel monotherapy [40.0\%]) (Table 4). During first-line therapy, doxorubicin plus ifosfamide was received by $3.0 \%$ and ifosfamide monotherapy was received by $2.7 \%$ of patients. Among all patients who received doxorubicin alone or a doxorubicin-based first-line therapy $(\mathrm{n}=371), 29.7 \%$ received liposomal doxorubicin, and 5.9\% received the cardioprotective agent dexrazoxane.

Among patients who received second-line $(\mathrm{n}=476)$ and third-line $(\mathrm{n}=189)$ therapy, doxorubicin monotherapy (second line, 21.2\%; third line, 14.8\%), docetaxel plus gemcitabine (second line, 17.4\%; third line, 11.1\%), and gemcitabine monotherapy (second line, 8.6\%; third line, $11.1 \%$ ) were most common (Table 4). Among the 476 patients who received second-line therapy, the most common treatment sequence was first-line docetaxel plus gemcitabine followed by second-line doxorubicin monotherapy $(\mathrm{n}=56,11.8 \%)$. Among the 189 patients who received third-line therapy, the most common sequence was first-line doxorubicin followed by second-line gemcitabine and then third-line docetaxel plus gemcitabine $(\mathrm{n} \leq 11)$. Among patients who received second- or thirdline therapy, $\leq 11$ received dexrazoxane.

Among patients who received supportive care only $(\mathrm{n}=1618,37.86 \%)$, the mean (SD) age was $80.0(7.5)$ years (Additional file 1: Table S1). Hypertension (69.6\%), diabetes without complications (28.7\%), chronic pulmonary disease $(28.1 \%)$, congestive heart failure (24.5\%), and peripheral vascular disease $(22.6 \%)$ were the most common baseline comorbidities and the mean (SD) CCI score was 3.1 (2.6).

The majority of patients $(\mathrm{n}=3565 ; 83.4 \%)$ died during study follow-up, with a median survival $(95 \% \mathrm{CI})$ of 8.9 months $(8.3,9.7)$ from the time of advanced STS diagnosis. Median survival (95\% CI) from advanced STS diagnosis among patients who received cancer-directed therapy was 13.6 months $(12.9,14.6)$, and among those who received supportive care it was 2.8 months (2.6, 3.4) (Table 5 and Fig. 1). Survival estimates for each histologic category is shown in Table 5. Estimated survival from advanced STS diagnosis varied by histologic category with median survival ranging from 21.4 months (15.6, 26.8) for patients with fibroblastic/myofibroblastic sarcoma to 3.0 months $(1.8,5.7)$ for patients with rhabdomyosarcoma.

\section{Discussion}

This study assessed recent real-world treatment patterns and estimated survival of a population-based cohort of older adults diagnosed with advanced STS in the US. More than $60 \%$ of patients were initially diagnosed at an earlier stage of disease and progressed to advanced STS with mean time to progression of 16.6 months. Consistent with previous studies [25-27], leiomyosarcoma, UPS and liposarcoma were the most common histological categories of STS in this study population.

Among patients initiating first-line systemic therapy, the most common regimen was docetaxel plus gemcitabine combination therapy (26.5\%); the next most common first-line regimen (18.8\%) was doxorubicin only. Both a recent medical record review study in the US [25] and the Sarcoma Treatment and Burden of Illness in North America and Europe chart review study [26] found that anthracyclines were used most commonly among first-line therapies (either alone or in combination) in younger patient populations. In this study of older adults, docetaxel plus gemcitabine was the most commonly used first-line therapy for most histologic categories except for vascular sarcomas (for which paclitaxel was most commonly used) and liposarcoma (for which doxorubicin was most commonly used). The use of paclitaxel for vascular sarcomas is consistent with evidence suggesting that vascular sarcomas may be relatively more responsive to taxanes and as such are recommended by NCCN guidelines [24, 28-30]. A relatively lower use of doxorubicin or related drugs was observed in this study, plausibly because the older age of the study population (mean age, 77.8 years) may increase concerns about adverse events, particularly doxorubicin-associated cardiotoxicity [27]. In the current study, $18.3 \%$ of the patients had a history of congestive heart failure and $25.8 \%$ of patients had a history of chronic pulmonary disease. Additionally, 69.2\% of the patients in this study had hypertension that, along with age, is known to increase the risk of doxorubicinassociated cardiotoxicity [31, 32]. Prior research has addressed the issues of doxorubicin-based therapies and cardiovascular risk factors in the older adult population [33-35]. It is possible that the low use of doxorubicin observed in this study cohort is related to these issues, but the study design and available data do not allow for a thorough investigation of this potential relationship. Further understanding of physician preferences with regard to administration of doxorubicin-based therapy among older adult patients is needed to adequately comprehend observed treatment patterns. Knowledge about the appropriate care of the older patient remains limited, but data from this study begin to fill this gap and suggest directions for future research related to toxicity risk, disease progression, recurrence and survival outcomes, and their relationship with patient age in the setting of advanced STS.

As observed in other studies, gemcitabine was used most commonly during second-line therapy (either alone or in combination) $[25,26]$. We also noted that 
Table 4 Top 5 most frequent regimens during first-, second-, and third-line therapy

\begin{tabular}{|c|c|c|c|c|c|}
\hline $\begin{array}{l}\text { First-line therapy } \\
\text { All patients }(N=1227)\end{array}$ & n (\%) & $\begin{array}{l}\text { Second-line therapy } \\
\text { All patients }(\mathrm{N}=476)\end{array}$ & n (\%) & $\begin{array}{l}\text { Third-line therapy } \\
\text { All patients }(\mathrm{N}=189)\end{array}$ & n (\%) \\
\hline Docetaxel-gemcitabine & $325(26.5)$ & Doxorubicin & $101(21.2)$ & Doxorubicin & $28(14.8)$ \\
\hline Doxorubicin & $231(18.8)$ & Docetaxel-gemcitabine & $83(17.4)$ & Docetaxel-gemcitabine & $21(11.1)$ \\
\hline Gemcitabine & $112(9.1)$ & Gemcitabine & $41(8.6)$ & Gemcitabine & $21(11.1)$ \\
\hline Paclitaxel & $68(5.5)$ & Paclitaxel & $21(4.4)$ & Ifosfamide & $15(7.9)$ \\
\hline Bevacizumab & $41(3.3)$ & Ifosfamide & $20(4.2)$ & Dacarbazine & - \\
\hline Leiomyosarcomas $(\mathrm{N}=341$ ) & & Leiomyosarcomas $(\mathrm{N}=148)$ & & Leiomyosarcomas $(\mathrm{N}=66)$ & \\
\hline Docetaxel-gemcitabine & $136(39.9)$ & Doxorubicin & $41(27.7)$ & Doxorubicin & $12(18.2)$ \\
\hline Doxorubicin & $64(18.8)$ & Docetaxel-gemcitabine & $35(23.7)$ & Docetaxel-gemcitabine & - \\
\hline Gemcitabine & $43(12.6)$ & Gemcitabine & - & Gemcitabine & - \\
\hline Carboplatin-paclitaxel & - & Docetaxel & - & Carboplatin-paclitaxel & - \\
\hline Dacarbazine-doxorubicin & - & Dacarbazine & - & Ifosfamide & - \\
\hline Doxorubicin-ifosfamide & - & & & & \\
\hline Temozolomide & - & & & & \\
\hline $\begin{array}{l}\text { Undifferentiated pleomorphic sarcoma } \\
(N=158)\end{array}$ & & $\begin{array}{l}\text { Undifferentiated pleomorphic } \\
\text { sarcoma }(\mathrm{N}=64)\end{array}$ & & $\begin{array}{l}\text { Undifferentiated } \\
\text { pleomorphic sarcoma } \\
(\mathrm{N}=24)\end{array}$ & \\
\hline Docetaxel-gemcitabine & $36(22.8)$ & Docetaxel-gemcitabine & $13(20.3)$ & Doxorubicin & - \\
\hline Doxorubicin & $32(20.3)$ & Doxorubicin & - & Docetaxel-gemcitabine & - \\
\hline Gemcitabine & $13(8.2)$ & Ifosfamide & - & Dacarbazine & - \\
\hline Ifosfamide & $11(7.0)$ & Gemcitabine & - & Ifosfamide & - \\
\hline \multirow[t]{2}{*}{ Doxorubicin-ifosfamide } & - & Paclitaxel & - & & \\
\hline & & Temozolomide & - & & \\
\hline Liposarcomas $(\mathrm{N}=140)$ & & Liposarcomas $(\mathrm{N}=45)$ & & Liposarcomas $(\mathrm{N}=15)$ & \\
\hline Doxorubicin & $34(24.3)$ & Docetaxel-gemcitabine & $11(24.4)$ & Ifosfamide & - \\
\hline Docetaxel-gemcitabine & $31(22.1)$ & Doxorubicin & - & Gemcitabine & - \\
\hline Bevacizumab & $13(9.3)$ & Gemcitabine & - & & \\
\hline Gemcitabine & $12(8.6)$ & Docetaxel-doxorubicin-gemcitabine & - & & \\
\hline Doxorubicin-ifosfamide & - & Ifosfamide & - & & \\
\hline Ifosfamide & - & & & & \\
\hline Vascular sarcomas $(\mathrm{N}=130)$ & & Vascular sarcomas $(\mathrm{N}=60)$ & & Vascular sarcomas $(\mathrm{N}=21)$ & \\
\hline Paclitaxel & $52(40.0)$ & Doxorubicin & $18(30.0)$ & Doxorubicin & - \\
\hline Doxorubicin & $22(16.9)$ & Paclitaxel & - & Doxorubicin-ifosfamide & - \\
\hline Docetaxel-gemcitabine & - & Docetaxel-gemcitabine & - & Docetaxel & - \\
\hline Doxorubicin-ifosfamide & - & Gemcitabine & - & Docetaxel-gemcitabine & - \\
\hline Docetaxel & - & Docetaxel & - & Paclitaxel & - \\
\hline $\begin{array}{l}\text { Fibroblastic/Myofibroblastic sarcomas } \\
(\mathrm{N}=58)\end{array}$ & & $\begin{array}{l}\text { Fibroblastic/Myofibroblastic } \\
\text { sarcomas }(\mathrm{N}=19)\end{array}$ & & $\begin{array}{l}\text { Fibroblastic/ } \\
\text { Myofibroblastic sarcomas } \\
(\mathrm{N}=-)\end{array}$ & \\
\hline Docetaxel-gemcitabine & $16(27.6)$ & Bevacizumab & - & Docetaxel-gemcitabine & - \\
\hline Doxorubicin & - & Docetaxel-gemcitabine & - & Gemcitabine & - \\
\hline Bevacizumab & - & Bevacizumab-temozolomide & - & & \\
\hline Gemcitabine & - & Gemcitabine & - & & \\
\hline Cisplatin & - & Temozolomide & - & & \\
\hline Doxorubicin-ifosfamide & - & & & & \\
\hline
\end{tabular}


Table 4 (continued)

\begin{tabular}{|c|c|c|c|c|c|}
\hline Nerve sheath sarcomas $(\mathrm{N}=24)$ & & Nerve sheath sarcomas $(\mathrm{N}=-)$ & & $\begin{array}{l}\text { Nerve sheath sarcomas } \\
(\mathrm{N}=-)\end{array}$ & \\
\hline Doxorubicin & - & Doxorubicin & - & & \\
\hline Docetaxel-gemcitabine & - & & & & \\
\hline Gemcitabine & - & & & & \\
\hline Doxorubicin-ifosfamide & - & & & & \\
\hline Ifosfamide & - & & & & \\
\hline Rhabdomyosarcomas ( $\mathrm{N}=28$ ) & & Rhabdomyosarcomas $(\mathrm{N}=15)$ & & $\begin{array}{l}\text { Rhabdomyosarcomas } \\
(\mathrm{N}=-)\end{array}$ & \\
\hline Docetaxel-gemcitabine & - & Doxorubicin & - & & \\
\hline Carboplatin-paclitaxel & - & $\begin{array}{l}\text { Cyclophosphamide-doxorubicin- } \\
\text { vincristine }\end{array}$ & - & & \\
\hline Cyclophosphamide-dactinomycin-vincristine & - & & & & \\
\hline Cyclophosphamide-doxorubicin & - & & & & \\
\hline Cyclophosphamide-doxorubicin-vincristine & - & & & & \\
\hline Doxorubicin & - & & & & \\
\hline Synovial sarcomas $(\mathrm{N}=21)$ & & Synovial sarcomas $(\mathrm{N}=-)$ & & Synovial sarcomas $(\mathrm{N}=-)$ & \\
\hline Docetaxel-gemcitabine & - & Dacarbazine & - & & \\
\hline Doxorubicin & - & Doxorubicin & - & & \\
\hline Temozolomide & - & Ifosfamide & - & & \\
\hline Others/NOS $(\mathrm{N}=327)$ & & Others/NOS $(\mathrm{N}=109)$ & & Others/NOS $(\mathrm{N}=46)$ & \\
\hline Docetaxel-gemcitabine & $81(24.8)$ & Docetaxel-gemcitabine & $14(12.8)$ & Gemcitabine & - \\
\hline Doxorubicin & $61(18.7)$ & Doxorubicin & $14(12.8)$ & Ifosfamide & - \\
\hline Gemcitabine & $30(9.2)$ & Gemcitabine & $12(11.0)$ & Dacarbazine & - \\
\hline Carboplatin-paclitaxel & $16(4.9)$ & Carboplatin-paclitaxel & - & Docetaxel-gemcitabine & - \\
\hline \multirow[t]{3}{*}{ Paclitaxel } & $12(3.7)$ & Docetaxel & - & Doxorubicin & - \\
\hline & & Doxorubicin-ifosfamide & - & & \\
\hline & & Ifosfamide & - & & \\
\hline
\end{tabular}

Only showing treatment regimens received by more than 1 patient

NOS not otherwise specified

dexrazoxane was not at all commonly used in this population among those who were treated with doxorubicin.

Approximately $62 \%$ of the study population received cancer-directed therapy. As compared to patients receiving cancer-directed therapy, patients receiving supportive care only had a mean age of 80.0 years (cancer-directed therapy: 76.5 years) at the time of being diagnosed with advanced disease and had a baseline comorbidity burden (mean CCI score) of 3.1 (cancerdirected therapy: 2.5 ), and $24.5 \%$ (cancer-directed therapy: $14.6 \%)$ had a history of congestive heart failure. Therefore, it seems likely that many of these patients may have been considered to not be candidates for chemotherapy, particularly with a cardiotoxic agent. The mean non-cancer CCI scores observed in this study for the overall population, patients receiving cancerdirected treatment, and patients receiving supportive care only are in line with those reported by Davis et al. among metastatic lung cancer patients [36].

Median overall survival in the entire study population was estimated to be less than 9 months. Patients who received supportive care lived only less than 3 months. The shorter survival of the group that received only supportive care, in addition to being related to not receiving anticancer treatment per se, is likely to be confounded by selection of patients for treatment who had a more favorable prognosis or better ability to tolerate treatment.

A study by Italiano et al. [7] (median age range 53-59 years), which included patients from the time frame of this study (i.e., 2002-2006), found that patients with synchronous or metachronous metastatic STS had an overall survival of 18 months from the time of metastatic diagnosis. Patients in the study by Italiano et al. [7] had relatively longer survival than those in this study, plausibly because patients in this study were considerably 
Table 5 Overall survival by treatment status and histologic categories

\begin{tabular}{|c|c|c|c|c|c|c|}
\hline \multirow[t]{2}{*}{ Overall } & \multicolumn{6}{|c|}{ Survival from initial diagnosis of advanced STS } \\
\hline & Total & Died & Censored & $\begin{array}{l}\text { Median length } \\
\text { of survival (in months) }\end{array}$ & $95 \% \mathrm{Cl}$ & \\
\hline All advanced STS patients & 4274 & 3565 & 709 & 8.9 & 8.3 & 9.7 \\
\hline \multicolumn{7}{|l|}{ Treatment status } \\
\hline Received cancer-directed treatment & 2656 & 2185 & 471 & 13.6 & 12.9 & 14.6 \\
\hline Received supportive care only & 1618 & 1380 & 238 & 2.8 & 2.6 & 3.4 \\
\hline \multicolumn{7}{|l|}{ Histologic categories } \\
\hline Fibroblastic/myofibroblastic sarcomas & 227 & 160 & 67 & 21.4 & 15.6 & 26.8 \\
\hline Leiomyosarcomas & 922 & 781 & 141 & 12.9 & 10.9 & 14.6 \\
\hline Liposarcomas & 554 & 395 & 159 & 21.1 & 17.4 & 27.1 \\
\hline Nerve sheath sarcomas & 106 & 88 & 18 & 6.2 & 3.6 & 9.3 \\
\hline Rhabdomyosarcomas & 98 & - & - & 3.0 & 1.8 & 5.7 \\
\hline Synovial sarcomas & 49 & - & - & 8.6 & 5.3 & 13.8 \\
\hline Undifferentiated pleomorphic sarcomas & 652 & 539 & 113 & 9.6 & 8.2 & 11.4 \\
\hline Vascular sarcomas & 357 & 327 & 30 & 6.0 & 4.8 & 7.3 \\
\hline Others/NOS & 1309 & 1139 & 170 & 5.4 & 4.8 & 6.1 \\
\hline
\end{tabular}

Cl confidence interval, NOS not otherwise specified, STS soft-tissue sarcoma

older. Similar to this study, survival did vary by histologic category in the study by Italiano et al. [7]. For example, patients with leiomyosarcoma, UPS, and nerve sheath sarcoma had a median survival of 12.9, 9.6, and 6.2 months, respectively, in this study and 19.4, 11.2, and 8.6 months, respectively, in the Italiano et al. [7] study.

An array of treatments (e.g. eribulin, olaratumab, pazopanib, trabectedin) became available for this population in the last decade [11, 13, 14, 37]; however, effectiveness of these treatments specifically among older adult patients with advanced STS is yet to established. Other treatments like oral cyclophosphamide plus prednisone [34] may also be feasible for older adult patients for whom treatment with doxorubicin may not be an option. Overall survival, progression-free survival, and response rates of patients with advanced STS may improve as these treatments will become part of routine care provided to this population.

This study is subject to several limitations inherent in analyses of Medicare claims data and the use of such data in studies of advanced cancer, in particular. For patients who were not initially diagnosed at the metastatic stage of the disease, ICD-9-CM diagnosis codes were used to identify evidence of metastatic disease during the follow-up period. However, the use of ICD-9-CM codes to identify metastatic disease has been shown to have sensitivity, specificity, and positive predictive value of less than $80 \%$, and thus the use of ICD-9-CM diagnosis codes in the Medicare claims data may have resulted in inaccurate or under-identification of an advanced STS population $[38,39]$. As described in the study methods, one of the criteria used to identify progression to metastatic disease was the initiation of systemic therapy at least 6 months after surgery. This criterion may have resulted in selection bias because patients who had disease progression but did not receive systemic therapy would have been omitted from the supportive care-only group. Although, the 6-month lag period after surgery was used to avoid interpreting adjuvant therapy as treatment for advanced disease, patients who progressed and received systemic therapy for advanced disease would have been omitted from the cancer-directed therapy group. Lines of therapy are not reported in claims data; therefore, an algorithm had to be defined to estimate the lines of therapy. This may have misclassified treatments by line of therapy, as the reasons for treatment changes were not available in the data. The Medicare Part D database was available for only a subset of the cohort (32.4\%); however, only a small proportion of all chemotherapy (2\%) claims were identified from the Medicare Part D database, so the risk of missing important treatment data is relatively low despite this limitation. An array of treatments (i.e., eribulin, olaratumab, pazopanib, trabectedin) became available for this population in the last decade, although these agents are not fully represented in the study dataset. Future research should evaluate the use and outcomes of these novel treatments in the older adult population. Finally, this study included only patients aged 65 years or older, and although SEER-Medicare data is representative of the US population 65 years and older for age and gender, participating SEER sites may not be representative with regard to distribution of race, income, urban residence, 

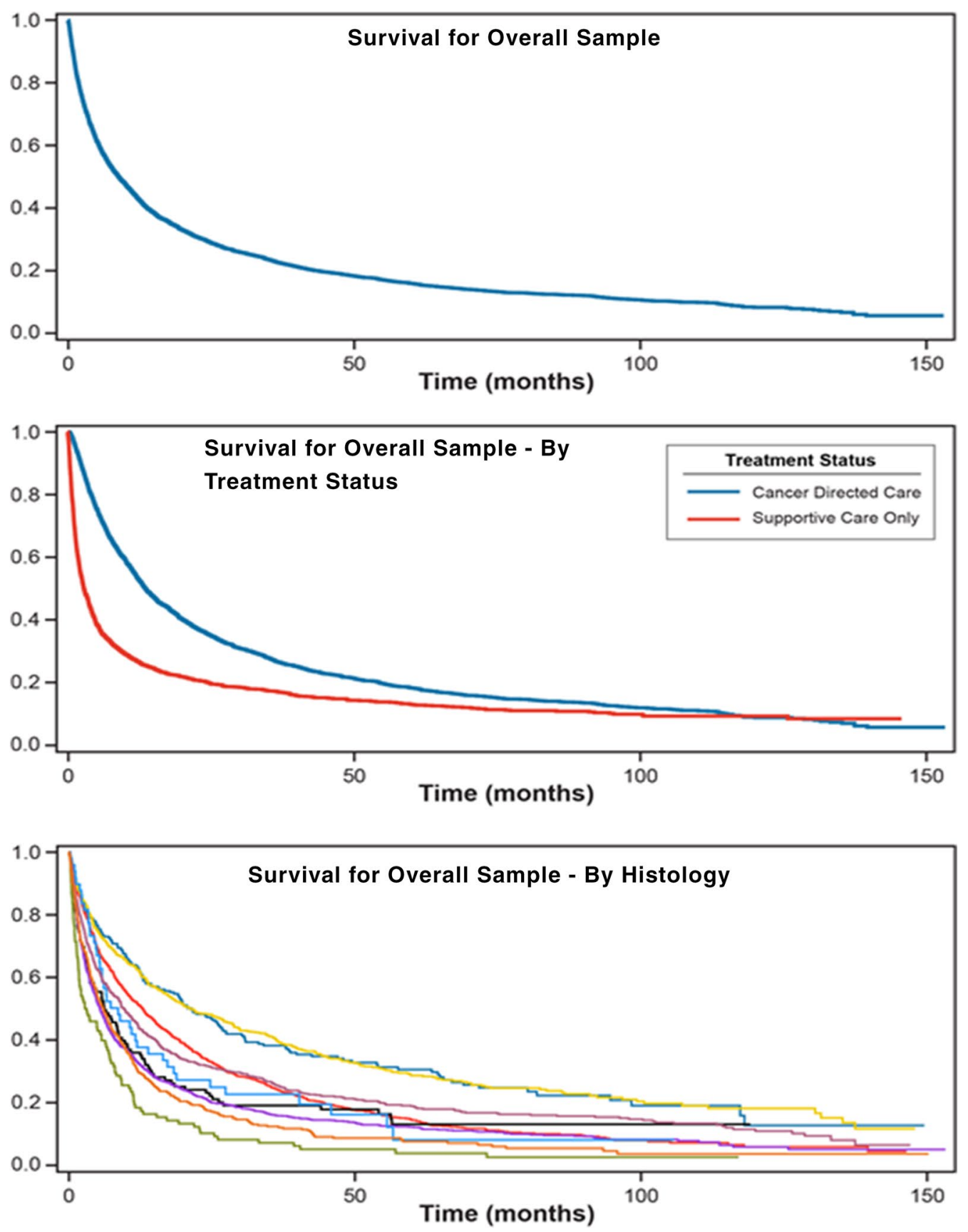

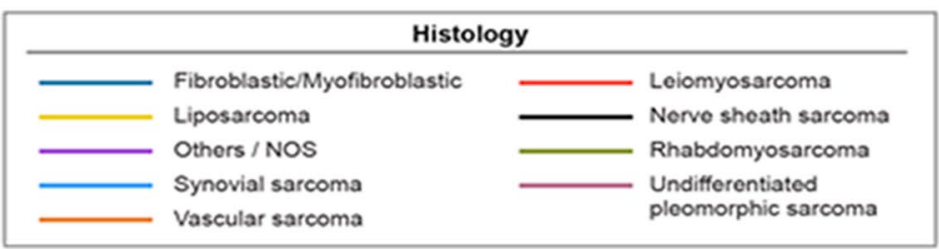

Fig. 1 Survival estimates from diagnosis of advanced soft-tissue sarcoma 
HMO enrollment as well as cancer mortality [15] and thus the results should not be generalized to the entire population of older adult patients with advanced STS.

Despite these limitations, this study documents realworld treatment patterns that may help inform providers, researchers, and policymakers about the care of older patients with STS in the US. As real-world data including new therapeutic options become available, our results provide a basis for analyzing changes in treatment patterns and outcomes over time. This study demonstrates that the prognosis is poor for older adult patients with advanced STS, highlighting the unmet medical need in this population.

\section{Conclusion}

Although previous studies of younger populations reported anthracycline-based therapy predominated in first line, our study of older adults with advanced STS found that doxorubicin was not commonly used. Despite variation by histologic category, prognosis was observed to be poor for older adult patients with advanced STS in this study.

\section{Additional file}

Additional file 1: Table S1. Patient Characteristics by Treatment Status (Received Cancer-Directed Treatment or Supportive Care Only).

\section{Abbreviations}

CCI: Charlson Comorbidity Index; Cl: confidence interval; HCPCS: Healthcare Common Procedure Coding System; ICD-9-CM: International Classification of Diseases, 9th Revision, Clinical Modification; ICD-O-3: International Classification of Diseases for Oncology, 3rd Edition; NCCN: National Comprehensive Cancer Network; NCI: National Cancer Institute; NOS: not otherwise specified; SD: standard deviation; SEER: The Surveillance, Epidemiology, and End Results; STS: soft-tissue sarcoma; UPS: undifferentiated pleomorphic sarcoma; US: United States.

\section{Authors' contributions}

All authors have participated in the content of the manuscript from initial study design, protocol development and interpretation of the data. RP drafted the manuscript and conducted the study analyses. All other authors contributed significant scientific/intellectual content and provided critical revisions to the draft manuscript. All authors meet the criteria for authorship in accordance with the authorship standards of the International Committee of Medical Journal Editors (ICMJE) Recommendations for the Conduct, Reporting, Editing and Publication of Scholarly Work in Medical Journals (http://www.ICMJE .org). All authors read and approved the final manuscript.

\section{Author details}

1 RTI Health Solutions, 200 Park Offices Drive, Research Triangle Park, NC 27560 , USA. ${ }^{2}$ Eli Lilly and Company Limited, Lilly Research Centre, Erl Wood Manor, Sunninghill Road, Windlesham, Surrey GU20 6PH, UK. ${ }^{3}$ Eli Lilly and Company, Lilly Corporate Center, Indianapolis, IN 46285, USA. ${ }^{4}$ RTI Health Solutions, 307 Waverley Oaks Road, Suite 101, Waltham, MA 02452, USA.

\section{Acknowledgements}

The authors acknowledge Eleanor Sibal (RTI Health Solutions) for medical writing support.

\section{Competing interests}

This study was performed under a research contract between RTI Health Solutions and Eli Lilly and Company and was funded by Eli Lilly and Company. RCP, SDC, and JAK are salaried employees of RTI Health Solutions. ML, LMH, and SN are salaried employees of Eli Lilly and Company.

\section{Availability of data and materials}

The SEER-Medicare dataset is available at https://healthcaredelivery.cance r.gov/seermedicare/obtain/.

\section{Consent for publication \\ Not applicable.}

\section{Ethics approval and consent to participate}

This study was deemed exempt from Institutional Review Board in accordance with the US Code of Federal Regulations [45CFR46.101(b)] as the public use data do not contain any variables that could identify an individual subject either directly or indirectly.

Funding

This work was funded by Eli Lilly and Company, Indianapolis, IN, United States.

\section{Appendix 1}

See Table 6. 
Table 6 Advanced soft-tissue sarcoma histologic categories and subtypes. Source: World Health Organization [17]

Histologic subtype (ICD-0-3) Description ${ }^{\mathrm{a}}$

Fibroblastic/myofibroblastic sarcomas

$$
\begin{aligned}
& 8810 / 3 \\
& 8811 / 3 \\
& 8814 / 3 \\
& 8815 / 3 \\
& 8825 / 3 \\
& 8832 / 3
\end{aligned}
$$

Leiomyosarcomas

$8890 / 3$

$8891 / 3$

$8896 / 3$

Liposarcomas

$8850 / 3$

$8851 / 3$

$8852 / 3$

$8853 / 3$

$8854 / 3$

$8855 / 3$

$8857 / 3$

$8858 / 3$

Nerve sheath sarcomas

$9540 / 3$

$9560 / 3$

$9561 / 3$

$9571 / 3$

$9580 / 3$

Others/NOS

$8800 / 3$

$8801 / 3$

$8802 / 3$

$8803 / 3$

$8804 / 3$

$8805 / 3$

$8806 / 3$

$8840 / 3$

$8842 / 3$

$8860 / 3$

$8894 / 3$

$8895 / 3$

$8940 / 3$

$8963 / 3$

$8982 / 3$

$8990 / 3$

$9020 / 3$

$9044 / 3$
Fibrosarcoma, NOS

Fibromyxosarcoma

Infantile fibrosarcoma

Solitary fibrous tumor, malignant

Myofibroblastic sarcoma

Dermatofibrosarcoma, NOS

Leiomyosarcoma, NOS

Epithelioid leiomyosarcoma

Myxoid leiomyosarcoma

Liposarcoma, NOS

Liposarcoma, well differentiated

Myxoid liposarcoma

Round cell liposarcoma

Pleomorphic liposarcoma

Mixed liposarcoma

Fibroblastic liposarcoma

Dedifferentiated liposarcoma

Malignant peripheral nerve sheath tumor

Malignant neurilemoma

Malignant triton tumor

Malignant Perineurioma

Malignant granular cell tumor

Sarcoma, NOS

Undifferentiated spindle cell sarcoma

Undifferentiated pleomorphic sarcoma

Undifferentiated round cell sarcoma

Undifferentiated epithelioid sarcoma

Undifferentiated sarcoma

Myxosarcoma

Ossifying fibromyxoid tumor, atypical

Angiomyolipoma

Angiomyosarcoma

Myosarcoma

Mixed tumor, malignant, NOS

Malignant rhabdoid tumor

Myoepithelial carcinoma

Mesenchymoma, malignant

\begin{tabular}{|c|c|}
\hline Histologic subtype (ICD-O-3) & Description $^{a}$ \\
\hline $9133 / 3$ & $\begin{array}{l}\text { Epithelioid hemangioendothelioma, } \\
\text { malignant }\end{array}$ \\
\hline $9231 / 3$ & Myxoid chondrosarcoma \\
\hline $9251 / 3$ & Malignant giant cell tumor of soft parts \\
\hline $9364 / 3$ & Peripheral neuroectodermal tumor \\
\hline \multicolumn{2}{|l|}{ Rhabdomyosarcomas } \\
\hline $8900 / 3$ & Rhabdomyosarcoma, NOS \\
\hline $8901 / 3$ & $\begin{array}{l}\text { Pleomorphic rhabdomyosarcoma, } \\
\text { adult type }\end{array}$ \\
\hline $8902 / 3$ & Mixed type rhabdomyosarcoma \\
\hline $8910 / 3$ & Embryonal rhabdomyosarcoma, NOS \\
\hline $8912 / 3$ & Spindle cell rhabdomyosarcoma \\
\hline $8920 / 3$ & Alveolar rhabdomyosarcoma \\
\hline \multicolumn{2}{|l|}{ Synovial sarcomas } \\
\hline $9040 / 3$ & Synovial sarcoma, NOS \\
\hline $9041 / 3$ & Synovial sarcoma, spindle cell \\
\hline $9042 / 3$ & Synovial sarcoma, epithelioid cell \\
\hline $9043 / 3$ & Synovial sarcoma, biphasic \\
\hline \multicolumn{2}{|c|}{$\begin{array}{l}\text { Undifferentiated pleomorphic sarcoma (previously known as malignant } \\
\text { fibrous histiocytoma or MFH) }\end{array}$} \\
\hline $8830 / 3$ & Malignant fibrous histiocytoma \\
\hline \multicolumn{2}{|l|}{ Vascular sarcomas } \\
\hline $9120 / 3$ & Hemangiosarcoma \\
\hline $9130 / 3$ & Hemangioendothelioma, malignant \\
\hline $9150 / 3$ & Hemangiopericytoma, malignant \\
\hline $9161 / 3$ & Hemangioblastoma; angioblastoma \\
\hline $9170 / 3$ & Lymphangiosarcoma \\
\hline
\end{tabular}

Phyllodes tumor, malignant

Clear cell sarcoma, NOS (except of kidney)
Desmoplastic small round cell tumor
Table 6 (continued)

NOS not otherwise specified

\section{Appendix 2}

See Table 7. 


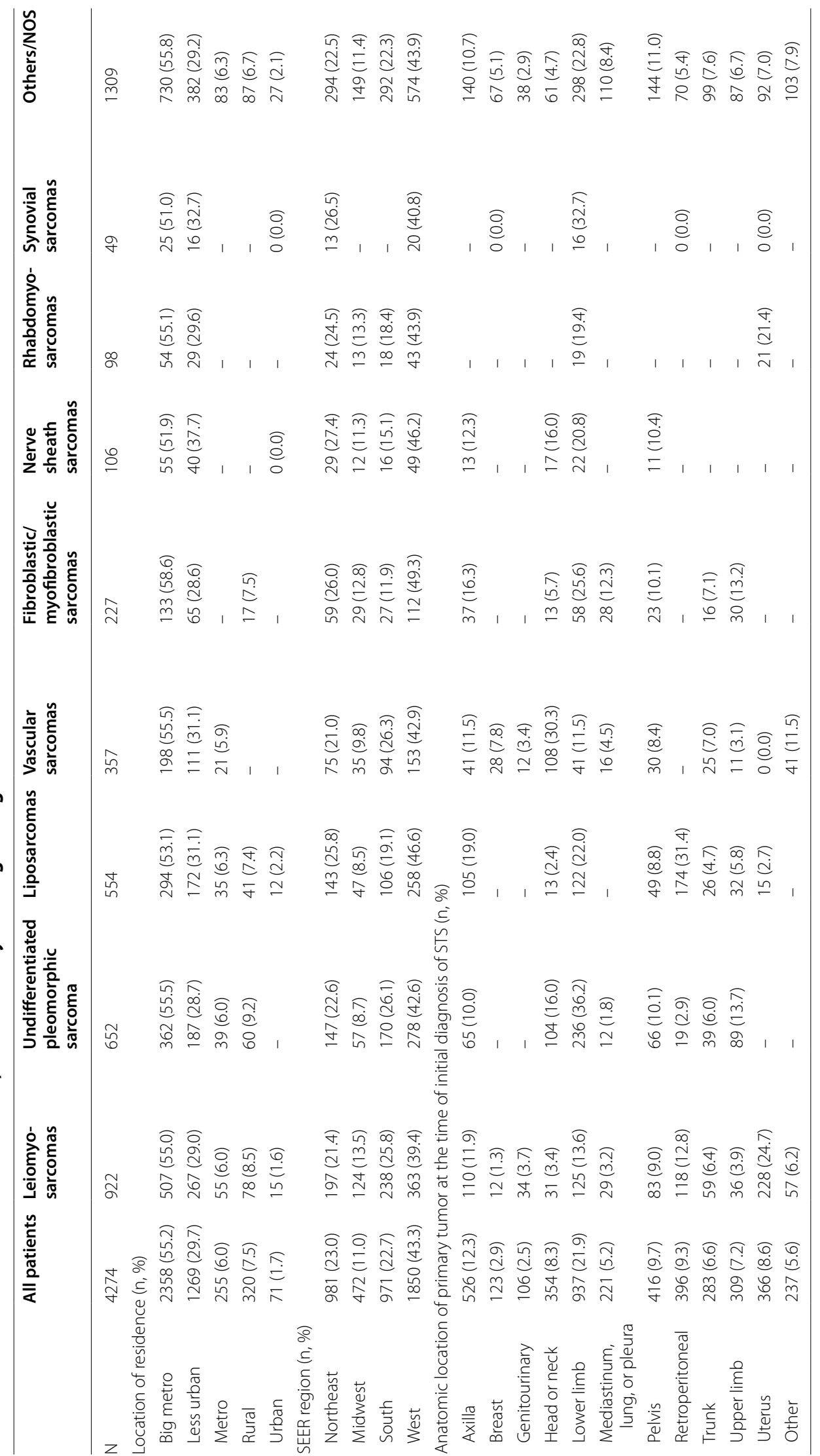




\section{Publisher's Note}

Springer Nature remains neutral with regard to jurisdictional claims in published maps and institutional affiliations.

Received: 27 October 2017 Accepted: 26 February 2018 Published online: 03 May 2018

\section{References}

1. Wibmer C, Leithner A, Zielonke N, Sperl M, Windhager R. Increasing incidence rates of soft tissue sarcomas? A population-based epidemiologic study and literature review. Ann Oncol. 2010;21(5):1106-11.

2. Siegel RL, Miller KD, Jemal A. Cancer statistics, 2018. CA Cancer J Clin. 2018;68:7-30

3. National Cancer Institute (NCI). Age-adjusted SEER incidence rates. https ://seer.cancer.gov/faststats/selections.php?series=age. Accessed $10 \mathrm{Jan}$ 2018

4. Schöffski P, Cornillie J, Wozniak A, Li H, Hompes D. Soft tissue sarcoma: an update on systemic treatment options for patients with advanced disease. Oncol Res Treat. 2014;37(6):355-62.

5. National Cancer Institute (NCI). Adult soft tissue sarcoma treatment (PDQ); 2017. https://www.cancer.gov/types/soft-tissue-sarcoma/patient/ adult-soft-tissue-treatment-pdq. Accessed 30 March 2017.

6. American Cancer Society (ACS). Survival by Stage of Soft Tissue Sarcoma; 2016. https://www.cancer.org/cancer/soft-tissue-sarcoma/detectiondiagnosis-staging/survival-rates.html. Accessed 21 Sept 2017.

7. Italiano A, Mathoulin-Pelissier S, Cesne AL, Terrier P, Bonvalot S, Collin F, et al. Trends in survival for patients with metastatic soft-tissue sarcoma. Cancer. 2011;117(5):1049-54.

8. Spira Al, Ettinger DS. The use of chemotherapy in soft-tissue sarcomas. Oncologist. 2002;7(4):348-59.

9. Karavasilis V, Seddon BM, Ashley S, Al-Muderis O, Fisher C, Judson I. Significant clinical benefit of first-line palliative chemotherapy in advanced soft-tissue sarcoma: retrospective analysis and identification of prognostic factors in 488 patients. Cancer. 2008;112(7):1585-91.

10. Judson I, Verweij J, Gelderblom H, Hartmann JT, Schöffski P, Blay JY, et al. Doxorubicin alone versus intensified doxorubicin plus ifosfamide for firstline treatment of advanced soft-tissue sarcoma: a randomised controlled phase 3 trial. Lancet Oncol. 2014;15(4):415-23.

11. Tap WD, Jones RL, Van Tine BA, Chmielowski B, Elias AD, Adkins D, et al. Olaratumab and doxorubicin versus doxorubicin alone for treatment of soft-tissue sarcoma: an open-label phase $1 \mathrm{~b}$ and randomised phase 2 trial. Lancet. 2016;388(10043):488-97.

12. United States Food and Drug Administration (FDA). FDA grants accelerated approval to new treatment for advanced soft tissue sarcoma [press release]; 2016. https://www.fda.gov/newsevents/newsroom/pressannou ncements/ucm525878.htm. Accessed 7 July 2017.

13. Demetri GD, Von Mehren M, Jones RL, Hensley ML, Schuetze SM, Staddon A, Milhem M, Elias A, Ganjoo K, Tawbi H, Van Tine BA. Efficacy and safety of trabectedin or dacarbazine for metastatic liposarcoma or leiomyosarcoma after failure of conventional chemotherapy: results of a phase III randomized multicenter clinical trial. J Clin Oncol. 2015;34(8):786-93.

14. van der Graaf WT, Blay JY, Chawla SP, Kim DW, Bui-Nguyen B, Casali PG, Schöffski P, Aglietta M, Staddon AP, Beppu Y, Le Cesne A. Pazopanib for metastatic soft-tissue sarcoma (PALETTE): a randomised, double-blind, placebo-controlled phase 3 trial. Lancet. 2012;379(9829):1879-86.

15. Warren JL, Klabunde CN, Schrag D, Bach PB, Riley GF. Overview of the SEER-Medicare data: content, research applications, and generalizability to the United States elderly population. Med Care. 2002;40(Suppl 8):IV-3-18.

16. Nattinger AB, McAuliffe TL, Schapira MM. Generalizability of the Surveillance, Epidemiology, and End Results registry population: factors relevant to epidemiologic and health care research. J Clin Epidemiol. 1997:50(8):939-45.

17. World Health Organization (WHO). International classification of diseases for oncology (ICD-O), 3rd edition, 1st revision; 2013. http://apps.who.int/iris/bitst ream/10665/96612/1/9789241548496_eng.pdf. Accessed June 2017.

18. Christopher DM, Fletcher JA, Bridge PC, editors. WHO classification of tumours of soft tissue and bone. 4th ed. Lyon: World Health Organization; 2013. p. 110-1.
19. American Joint Committee on Cancer. Cancer staging manual. 6th edition; 2002. https://cancerstaging.org/references-tools/deskreferences/ Pages/default.aspx. Accessed 26 June 2017.

20. National Cancer Institute (NCI). SEER summary staging manual_2000: codes and coding instructions; 2000. https://seer.cancer.gov/tools/ssm/. Accessed 9 June 2017.

21. Charlson ME, Pompei P, Ales KL, MacKenzie CR. A new method of classifying prognostic comorbidity in longitudinal studies: development and validation. J Chronic Dis. 1987;40(5):373-83.

22. Charlson ME, Charlson RE, Peterson JC, Marinopoulos SS, Briggs WM, Hollenberg JP. The Charlson Comorbidity Index is adapted to predict costs of chronic disease in primary care patients. J Clin Epidemiol. 2008:61(12):1234-40.

23. Deyo RA, Cherkin DC, Ciol MA. Adapting a clinical comorbidity index for use with ICD-9-CM administrative databases. J Clin Epidemiol. 1992:45(6):613-9.

24. National Comprehensive Cancer Network (NCCN). Soft tissue sarcoma. NCCN Clinical Practice Guidelines in Oncology; 2017 https://www.nccn. org/professionals/physician_gls/pdf/sarcoma.pdf. Accessed June 2017.

25. Wagner MJ, Amodu LI, Duh MS, Korves C, Solleza F, Manson SC, et al. A retrospective chart review of drug treatment patterns and clinical outcomes among patients with metastatic or recurrent soft tissue sarcoma refractory to one or more prior chemotherapy treatments. BMC Cancer. 2015:15:175.

26. Leahy M, Garcia Del Muro X, Reichardt P, Judson I, Staddon A, Verweij J, et al. Chemotherapy treatment patterns and clinical outcomes in patients with metastatic soft tissue sarcoma. The Sarcoma treatment and Burden of Illness in North America and Europe (SABINE) study. Ann Oncol. 2012;23(10):2763-70.

27. Matushansky I, Dela Cruz F, Insel BJ, Hershman DL, Neugut Al. Chemotherapy use in elderly patients with soft tissue sarcoma: a populationbased study. Cancer Invest. 2013;31(2):83-91.

28. Skubitz KM, Haddad PA. Paclitaxel and pegylated-liposomal doxorubicin are both active in angiosarcoma. Cancer. 2005;104(2):361-6.

29. Penel N, Bui BN, Bay JO, Cupissol D, Ray-Coquard I, Piperno-Neumann S, et al. Phase II trial of weekly paclitaxel for unresectable angiosarcoma: the ANGIOTAX Study. J Clin Oncol. 2008;26(32):5269-74.

30. Schlemmer M, Reichardt P, Verweij J, Hartmann JT, Judson I, Thyss A, et al. Paclitaxel in patients with advanced angiosarcomas of soft tissue: a retrospective study of the EORTC soft tissue and bone sarcoma group. Eur J Cancer. 2008;44(16):2433-6.

31. Chatterjee K, Zhang J, Honbo N, Karliner JS. Doxorubicin cardiomyopathy. Cardiology. 2010;115(2):155-62.

32. Volkova M, Russell R 3rd. Anthracycline cardiotoxicity: prevalence, pathogenesis and treatment. Curr Cardiol Rev. 2011;7(4):214-20.

33. Hershman DL, McBride RB, Eisenberger A, Tsai WY, Grann VR, Jacobson JS. Doxorubicin, cardiac risk factors, and cardiac toxicity in elderly patients with diffuse B-cell non-Hodgkin's lymphoma. J Clin Oncol. 2008;26(19):3159-65.

34. Mir O, Domont J, Cioffi A, Bonvalot S, Boulet B, Le Pechoux C, Terrier P, Spielmann M, Le Cesne A. Feasibility of metronomic oral cyclophosphamide plus prednisolone in elderly patients with inoperable or metastatic soft tissue sarcoma. Eur J Cancer. 2011:47(4):515-9.

35. Ferreira AL, Matsubara LS, Matsubara BB. Anthracycline-induced cardiotoxicity. Cardiovasc Hematol Agents Med Chem (Former Curr Med ChemistryCardiovasc Hematol Agents). 2008;6(4):278-81.

36. Davis KL, Goyal RK, Able SL, Brown J, Li L, Kaye JA. Real-world treatment patterns and costs in a US Medicare population with metastatic squamous non-small cell lung cancer. Lung Cancer. 2015;87(2):176-85.

37. Schöffski P, Chawla S, Maki RG, Italiano A, Gelderblom H, Choy E, et al. Eribulin versus dacarbazine in previously treated patients with advanced liposarcoma or leiomyosarcoma: a randomised, open-label, multicentre phase 3 trial. Lancet. 2016;387(10028):1629-37.

38. National Cancer Institute (NCI). Measures that are limited or not available in the data; 2015. https://healthcaredelivery.cancer.gov/seermedicare/ considerations/measures.html. Accessed 21 Sept 2017.

39. Chawla N, Yabroff KR, Mariotto A, McNeel TS, Schrag D, Warren JL. Limited validity of diagnosis codes in Medicare claims for identifying cancer metastases and inferring stage. Ann Epidemiol. 2014;24(9):666-72. 